ried on in a free-lance way, and not from specially twenty to twenty-five years of practical application organized houses. This is vouched for by the agents Europe had, according to her own report, by no means of various societies who have the doings of many of solved the problem of control or diminished the spread the keepers of such houses under surveilance, and of venereal disease. New methods, perhaps better, know that they have either left the city or are not certainly more inquisitional, have since been instigated, engaged in running houses of prostitution, though the results of which we have no means of knowing many are waiting for the first signs of relaxed activity and cannot have for some years to come; but from on the part of the police to open their houses once more. Some of the girls have gone to their homes, and many others have been found employment, and their movements are under the observation of the agents of various societies.

Is this for the better or worse? Has the dispersion of the prostitutes among a class of the people formerly free from their presence, and the possible increased danger to women from the assaults of men thus deprived of their customary sexual relief, made a coudition of things that is worse than the former free system? The latter argument does not seem to me to have any weight. The dangerous classes live so that it is possible for them to indulge in sexual intercourse at all times, and they cannot from the very necessity of their existence support the houses of prostitution and are consequently not affected by the change. If the fact that prostitutes are to be found in new quarters tends to raise a strong public sentiment among our all too easy-going people so that they are forced to recognize that this is an evil which must be met and dealt with in some way or other, not a mere abstract question which in no way concerns the average family or the average citizen, then I maintain that the evil of the dispersion is overbalanced by the good. On the other hand, the closure of the houses has removed a large amount of temptation from weak men, many of whom go to such places not for any purpose of gratification of strong sexual passion but simply "with the boys." Once there, they are filled with alcohol, robbed, and given disease. Furcher, the supply now exceeding the demand, there is less attempt to entrap young and previously innocent women for immoral purposes, neither is there such a free and easy opening for a girl made desperate by lack of work or previous disgrace to enter upon the life of a public prostitute, and hence it is much more easy for the agents of the numerous societies to get hold of her and keep or make her a respectable member of the community. Thus, and thus only can the number of prostitutes in our midst be made very gradually to diminish. This decrease could be materially hastened by lessening the number who are born prostitutes; for by castration and ovariectomy the persistent criminals and chronic paupers should be prevented from reproducing their kind, the female portion of which are practically born prostitutes.

In conclusion, I would say that I have looked over the discussion of the Contagious Disease Acts that took place in England during the period of 18701875 , and with very few changes the conditions were exactly the same as at the present time. There was the same amount of discouraging statistics from Paris and other Continental cities, the same demand for more frequent examinations and the same report of the impossibility of controlling all women engaged in the profession; the same statements that the number of licensed houses was decreasing, by some marked with apprehension. In fact, one of the greatest arguments which has been put into the hands of the won-recognition party is this fact, that at the end of their very diversity they furnish us with no indication of any sure course that here in Boston we should follow. There seems to be no other way open to us but to wait for a decade at least, until we find out what method offers the greatest chance of success in obtaining a real control over this evil. In the mean time it seems mandatory for us to pursue our present policy of repression of the evil to its smallest possible limits. And this can only be accomplished by a vigorous public sentiment which shall support enthusiastically the strong arm of the law in its work of repression under existing laws and shall make the increase in the ranks of prostitutes as small as possible - by every means which shall check the traffic in girls, by education of both boys and girls in our homes and schools, by a law which shall raise the age of consent, and by removing from the chronic criminal classes the power of reproduction of their species. At the same time the spread of venereal disease should be combated by hospital accommodations for those who are now debarred from proper medical care and treatment.

THE TREATMENT OF SCLEROSIS, OF VARIOUS FORMS OF PARALYSIS AND OTHER NERVOUS DERANGEMENTS, BY SUGGESTION.1

BY HAMILTON OSGOOD, M.D.

IN his work on Suggestion, Bernbeim reports a case (Observation VII) of disseminated sclerosis, which he treated by suggestion with such favorable results, that, after a few sittings the patient recovered the use of his limbs, trembling of the hands ceased and the man became a waiter in the wards of the hospital.

Elsewhere, Bernheim offers a reasonable explanation of this result. His theory is that the tissue of the spinal cord is not totally invaded by the sclerosis at the site of its existence; that by means of tissue as yet untouched by the pathological condition, it is still possible for the nerve force to pass on. This is clearly shown by the restoration of power to the arms aud legs of the patient in question.

This explanation seems logical and natural. Bernheim's patient continued six months in this condition of amelioration after the treatment had been discontinued. At the end of that time the former symptoms gradually returned and suggestion was not again applied.

The practical result of suggestion during sleep is an invigoration of functional power. A patient suffers from pain in the head, or in a joint, and there is a loss of function. The pain is relieved by suggestion and, unless it be deformed or inflamed, the patient can at once use the joint in a natural manner and again apply his mind to necessary work. Function has been restored. There are innumerable and similar illustrations.

In a case of sclerosis, or other affection of the cerebro-spinal axis, I have no doubt that the symptoms 1, Read before the Boston Society for Medical Improvement, April
1, 
are exaggerated, at all events exacerbated, by the mind of the patient and that, in consequence, there is a loss of functional power which, in the earlier stages of the disease is inconsistent with the actual condition of the tissue involved. That is to say, the actual functional possibilities are disturbed by the mental depression of the patient. In other words, but for the feeling of hopelessness which has taken possession of the mind of the patient, he might walk more naturally and use hands and arms with more ease.

Suggestion will not only arouse functional power but will stimulate mental vigor and displace depression by hope. So long then, in the cases in question, as there exists a possibility of the passage of nerve energy by means of tissue still unbarmed by the pathological process, the physician's duty seems clear. Stagnation of hope and of functional vigor in the patient should steadily be prevented. Let him, however, fall into hopeless despair, acquiesce even tacitly in his opinion that he has become helpless, incurable, useless, and he will simply go on from bad to worse. Such a state of mind on the part of the patient and such acquiescence on the part of the physician will basten the injurious effects of the disease.

It is necessary only to watch the mental condition of such a case to be convinced of the harm which the unsupported mind can create. Auy physician who has become habituated to the application of suggestion and whose custom it is to watch his patient's mind as well as his body, is surprised when he observes the indifference of the average physician to the mental condition of his patient.

There is nothing in life stronger than habit, whether muscular or mental. If the thought that he is helpless and that there is no bope for him be allowed to become a habit in the mind of a patient, it will be converted into injurious results as surely as the thought of a peach during thirst, will excite the salivary glauds, and both results will be involuntary and unconscious.

In 1893, at the Congress of Psychology in London, I heard a distinguished French professor read a paper on "'The Neglect of Mind by Physicians."

A few months ago while in conversation with Bérillon, of Paris, he suddeuly exclaimed, "Medicine is not taught in Paris." "What do you mean?" I asked. "Nothing is said about mind," he replied.

Still, almost unconsciously, thinking physicians are daily resorting more and more to the use of suggestion. This subtle power is slowly insinuating itself into the practice of medicine. Those physicians who oppose the direct use of a proper and intelligent application of hypnotic suggestion, believe they are correct in doing so. But practically they are actually unfamiliar with its benefits, and they are wholly mistaken in their assertions that it is dangerous, useless, humbug, etc. This treatment cannot be judged theoretically. One may theorize his life long about swimming, but, practically he has no right to an opinion until he has plunged in and has swum with his own arms and legs. There are so many illustrations of this purely theoretical scepticism in medicine, with reference to remedies which were thoroughly accepted when once they had been practically tried, that I need not adduce them.

With this digression, which was almost involuutary, I turn to an interesting case similar to that reported by Bernheim and aiready mentioned. The patient was referred to me by Dr. Scudder. Her history was given me by the patient herself.
A young lady, age twenty-two years, single, was seized, four years before I saw her, with numbness in the posterior aspect of the legs; her ankles turned at every step; she was very weak ; was fatigued by every movement; was very irritable. The family physician pronounced the trouble irritation of the nerves.

As months passed on the patient became worse. When three months had elapsed she could not walk at all, and then bad no control over either bowels or bladder. This condition passed off and, two months later, reappeared. The hands became numb, the fingers were spasmodically "drawn back"; there were severe headaches; patient was sick aud dizzy. During one month she lost control of the eyes. Had diplopia. Could not swallow liquids. Talking became difficult. A specialist pronounced the illness lead-poisoning. 'Treated for that ailment, patient became better. Later she was worse again. Went to the Adams Nerviue Asylum. Improved a little, then fell into a still worse condition. The disease was now said to be "spinal trouble."

Twelve months having elapsed, patient again had improved. Eighteeu months from first attack was worse again, and failed rapidly. Meanwhile she lost the use of her arms ; then regained power over them. Finally, the difficulty settled in the legs, and a specialist and the family physician diagnosticated lateral sclerosis. Two other physicians thought the ailment hysteria; and when I first saw the patient there were undoubted hysterical symptoms. But the patient could move neither legs nor feet. Lying upon the back aud in the sitting position she could not lift nor move either foot in the least and it was difficult for me to flex the legs. She had not stood once during the two previous years. The knee-jerks were much exaggerated and the ankle-clonus was very marked. There was no atrophy, the legs being large and heavy. Patient enjoyed perfect use of hands and arms. Organs and periods normal. Constipation moderate. Suggestion induced merely the first stage of somnolence, but the patient was very suggestible. 'This relation of one condition to the other is very frequent. During the waking state strong meral suasion was also used.

Patient began almost at once to move the legs, and her power over them increased daily. After the lapse of two or three weeks, whether sitting or lying, she could lift either leg normally. Gradually she moved about the house (St. Margaret's), went daily to the bath-room and finally did so without her cane. Meanwhile constipation had disappeared.

After seeing the patient almost every day for about seven weeks, $I$ sent her home with the promise that she would steadily improve. By this time the kneejerks and especially the ankle-clonus had become notably diminished. In fact, it became difficult and nearly impossible to create any sign of spasm in the foot.

Referring again to the hysterical aspects of the case, I will frankly confess that notwithstanding the long. existing loss of leg-power, the ankle-clonus and other abnormal reflex symptoms, $I$ found it difficult and puzzling to account for sclerosis in view of the following points, namely: total absence of the atrophy in spite of the very chronic nature of the disease; almost entire disappearance of exaggeration in the reflexes under suggestive treatment, and, further, the curious fact, mentioned by the mother of the patient, that on several occasions, during a period of perfect helplessness in waking hours, the invalid left her 
bed and walked naturally during her sleep, or in a condition of somnambulism. The mother is absolutely positive on this point, for she waked her daughter and forced her to return to her bed, the power of walking then abating. Nevertheless, as will be seen later, there finally was discovered an indisputable proof of the existence of sclerosis.

After her return to her home the patient wrote me very frequently, and always in a tone of cheer and hope. This evidence of a beneficial mental change was a wholly new thing as well as a source of great satisfaction to the patient's mother. During the next few months there was a slow but positive gain. Evidences of improvement were, however, somewhat intermittent. On a given day the patient could walk up and down stairs without help; on the following day she required assistance. One day she could enter a carriage unaided; on the next day it was necessary to lift her. On one day she appeared so able that her lack of power on the succeeding day led her friends to think she was shamming. She went about the house with the aid of a chair which she pushed before her.

She went out of doors in a wheeled chair, and finally when she had left the chair, seated herself upon the ground to pick violets, which she sent to me with a note, in which she expressed her happiness that she could do this, and afterward reseated herself in her chair without help; it became evident, notwithstanding the fact that the legs had not wholly recovered freedom, that the gain had been large.

During the next three months, being absent from the country, I did not hear from the patient, but her mother assures me that there was no loss either in power or mental cheer.

A note from the patient's mother says: "Fannie was able to go up and down stairs on her feet several times last summer. She took hold of the bannister and went up alone although it was hard for her. Sometimes she could walk down slowly; sometimes she would sit and slip down one stair at a time. I have known her to walk well when asleep though she could not walk without assistance when awake. But she has not done this since you have known her, not later than January, 1892."

In December last the patient fell ill, and died of pyelo-nephritis. The autopsy revealed sclerosis in various districts of the spinal cord touching which I hope that Dr. J: J. Putnam will give further and more exact information.

In view of this revelation, the recovery and increase of ability to use the legs and the almost entire disappearance of the exaggerated character of the reflexes, may fairly be attributed to invigoration of function in response to suggestion. Had the patient contiuued to live, it is possible that unconquerable loss of power would some day have resulted. Nevertheless when we consider the fact that all other treatment had been abandoned as useless and that, when she came under the suggestive treatment, the patient was helpless, the hope and amelioration of symptoms conferred by this means of relief become sufficiently apparent. Van Renterghem and Van Erden report a similar case but in which the results produced by suggestion were not so effective.

$A$ Case af Paraplegia.-After months of treatment in a Lynn hospital, a young woman, age twentythree years, single, was admitted to the Home for Incurables, naturally as an incurable. Her ailment was paraplegia which had made such progress that the legs were atrophied to a degree which I have never witnessed in any other case. In brief, there was no muscle on the bones of the legs, and they bung from the hips like sticks, immovable and helpless. The condition was due to a heavy fall into the sitting posture. The patient, of course, could move neither legs nor feet, which it was constantly necessary to arrange and place for her. When put upon ber feet the patient collapsed and fell to the floor. She was badly constipated, had irritable bladder, spinal and cranial pains, no ankle-clonus, slight exaggeration of the jerk of one knee. There was marked hysteria and mental irritability.

Here, surely was an unpromising case. But the patient proved to be an excellent subject; and on the 24th of January, 1890, I made my first suggestion. The patient fell into a profound sleep. Lifting one of her legs I suggested that she could not put it down. The limb remained in air a few seconds. This not only gave me hope but revealed an excellent means of diagnosis, for it became evident that the lesion of the spinal cord was largely if not wholly functional. The main argument against this supposition was the extreme and unusual degree of atrophy. After the necessary suggestion had been made the patient was aroused. She could then bear ber weight in the standing position. The knees occasionally yielded, but the patient showed more strength than had been evident during two years previously, and required little more support than was needed to steady her.

January 28th. During sleep patient's leg remained a longer time than before in raised position. After waking stood unaided twenty seconds.

January 31 st. Improvement steady. Suggestion. February 4 th and 9 th. Fourth and fifth treatments. Bladder and bowels show better condition. Patient can cross the legs.

February 14th to 28th. Five additional sittings. Patient can stand, lift the legs, cross and uncross them with ease.

The treatment was applied semi-weekly until April 30 th, by which time patient was walking with help. Bladder normal. Constipation gone, spinal and cephalic pain vanished, legs increused in size.

February 11, 1891. A lapse of nine months since I had last seen the patient. During the interval she had lost none of the new power, and was stronger on her feet; was less hysterical. Recommenced the treatment by suggesting that she would walk to church on Easter Sunday. This I obliged the patient to repeat after me during sleep. When that Sunday came patient did walk to church and by May 1st - for I again continued the treatment semi-weekly until that time - she went everywhere with ease. Meanwhile the legs had regained their normal size and strength. Patient in fine condition. Save an occasional indication of hysteria during the menstrual epoch nothing remained of the original ailments. To-day the young woman is an assistant in the Home and is in good health. Once before I published a meagre outline of this case but the final result had not then been reached.

Case of Paraplegia from heavy blow upon the head, fracturing the skull of a young man who was admitted to the Home for Incurables after having spent six months in the Massachusetts General Hospital. His body was supported by iron frames which enclosed the 
legs. By the additional help of crutches he could move slowly over short distances. There was cystitis and absolute incontinence of urine, a urinal being indispensable. Patient suffered from intense pain in right foot which no treatment at the Massachusetts General Hospital was able to relieve. A cradle was necessary to prevent pressure of bed clothing which patient could not bear.

He proved very suggestible, slept profoundly, was totally anesthetic and subsequently, while asleep, was unmindful of painful operations such as the curetting of the cavity of an old abscess. The first suggestion wholly and permanently relieved the pain in the foot. Subsequent suggestions gave steadily increasing power to the legs. At the end of three months the iron frames were discarded, crutches alone being sufficient and patient could walk with a crutch in each hand. The suggestions were renewed after a lapse of nine months and continued as before, twice weekly, during three months. No treatment has been given during the past two years. The cystitis meanwhile slowly decreased and to day incontinence is the only sign of vesical disorder. The patient wears no splint, walks easily with one crutch held in the hand, is in fairly robust health and does the lesser carpenter work of the house.

Paralysis of Tongue. - February 7, 1890. Six months ago a lawyer experienced a slight apopleptic attack, which, however, caused unconsciousness and a fall. Now, the lingual muscles are embarrassed. In distinct enunciation. Patient obliged to abandon pleading in court. Right arm very weak. Writing nearly impossible. Patient chronically constipated.

Following the first suggestion the tongue acted with greater freedom ; articulation clearer.

February 8th. The beneficial change remains. Second suggestion applied.

February 11th. Greater freedom of articulation is very noticeable and the right hand is more flexible in the use of a pen. Third suggestion.

February 12th. Fourth treatment. Improvement continues.

February 18th. Lapse of one week. Very marked gain in freedom of utterance; arm much more vigorous; bowels freer than they previously have been in ten years. Final suggestion applied. Patient began again to plead in court. When I last saw him, two years later, there had been no relapse.

Case of Paralysis Agitans in a weak old man of seventy years, with great lack of leg-power and coördination, the head drooping, spine bent forward, hands in constant agitation. This patient received large comfort from the suggestive treatment and begged for it. Following a suggestion the agitation of the hands disappeared either partially, or wholly, during several days. Walking was stronger, patient held himself erect, the forced adduction of the knees was relieved and there was ability to face about in the standing position which, before he received the treatment, the patient could not possibly accomplish. He declared that during the sleep and after waking he was conscious of a warm current of stimulation in arms and legs. At the end of three or four days this renewed vigor gradually disappeared to be restored by a fresh suggestion. In this case the treatment gave amelioration and comfort which no other means could have supplied. The general health of the patient improved and undoubtedly his feeble hold upon life was thus prolonged.
$A$ Case of Hemiplegia. Male, aged sixty. Patient able to move about a little. Could not lift the paralyzed arm above a level half-way between hip and shoulder. Grip very feeble. After the first suggestion patient voluntarily said that he felt a hot sensation in arm and leg of affected side. Could raise the arm to the level of the head. After second sitting could raise the arm straight above the head and felt stronger on the weak leg.

Treatment continued at intervals during three months. Patient gained large control of the arm, had a stronger grip, could walk long distances.

Some months later this man died of an intercurrent disease. Beruheim has reported similar cases with even better results.

Case of Paraplegia, due to a fall from one story to another through a hatchway, ten years before I saw the patient, a gentleman, aged sixty. He received the suggestive treatment two or three times weekly during a period of five months, advancing slowly but steadily to a more manageable condition of the legs which felt lighter and more alive. I have not seen this patient for two years, but he writes that some months after I last saw him he became weaker again. In such cases amelioration naturally is all that suggestion can effect.

Case of Tremor of the Hands, in a lad of twenty years, which prevented work of any kind. Patient had formerly used tea and tobacco excessively, had masturbated much and was mentally agitated. Suffered from insomnia. Was treated by suggestion once weekly during five weeks. The first treatment quieted the hands and wholly relieved the insomnia. The effect was intensified by each successive sitting. After the fifth suggestion patient could strike with unering exactness a given spot on wall-paper with the point of a pencil beld by the tips of the fingers. Patient said he had abandoned the habit of masturbation. Recovery and no relapse.

Case of Tremor of the Right Hand, with loss of muscular power, insomnia, spinal pain, incontinence of urine, pain in walking in a lady aged sixty, married, in whom there was not a vestige of hysteria. She received sixteen treatments by suggestion, which relieved ber of incontinence, lameness; spinal pain and insomnia, restoring strength and perfect quiet to the hand and arm, patient being able easily to thread a needle. Twelve months have passed since the last sittiug. There has been no relapse.

Case of Chorea, of seven years' duration, in a young lady aged nineteen. Movements moderate in character. After first suggestion there was greater quiet. Following five additional applications the patient did not improve. The treatment was then abandoned.

Chorea in a boy of twelve years, who presented constant movement of head, arms and face. He received twenty-four treatments, improved rapidly and promised recovery. The treatment ceased abruptly because patient was removed from the city.

Chorea in a boy of eight years. Twitching of eyes, brows and lips. He received fifteen applications of suggestion. 'To-day, unless fatigued or excited, he shows no choreic symptoms.

Chorea since Childhood in a young man aged twenty-four. A severe case. Patient a masturbator. Received twenty-four treatments with slight improvement which was not permanent. 
Case of Stammering in a gentleman of thirty years. Stuttered very badly. Had sought relief at home and in Europe since childhood. A good subject, slept profoundly. He received $10+$ applications of suggestion. The stammering decreased steadily and remarkably. At the present time, after a lapse of three years, unless excited or embarrassed, the patient speaks smoothly and connectedly.

My experience with cases of stammering has led me to believe that the mind stammers as well as the muscles and the suggestion that, during speech, there will be an undisturbed tranquillity of mind, is one of which I always make use. In a susceptible person this will cause a less interrupted nerve discharge. In addition to this $I$ suggest perfect repose and freedom from all spasmodic movements of the diaphragm.

The longer the affection has lasted and the more pronounced the stammering, the greater the number of applications of suggestion should be. It is needful to create another mental and another muscular habit. This requires time.

Case of Stammering in a student of Harvard University. He stammered in every sentence but not nearly so badly as did the former case. After the first suggestion patient did not stammer once during half the next day. Then the trouble returned. Following second sitting the effect was more prolonged. A few successive treatments disposed of the affection and two years later patient reports that he is still free from it.

Case of Stammering in a young lady whose speech broke every few words. After two sittings she thought herself somewhat relieved. After the ninth patient was in doubt. Received fifteen treatments in all after which she was certain of marked improvement but has never been wholly free from the annoyance.

Case of Chronic Retention of Urine in a young man from spasm of the urethra. Relieved permanently by five treatments.

The cases which I have reported sufficiently show the usefulness and occasional failure of the suggestive treatment, which, like other remedies, but in my experience less often than they do, meets with disappointment. I think, however, that I have indicated the beneficial effects of suggestion in ailments of a peculiarly unyielding nature and which I purposely' selected from my record-book, in order to make clear that such forms of illness, having defied other means of relief, still have a friend in suggestion, which, while it may not always bring recovery, will, in susceptible persons, often confer the comforts of amelioration.

It is needless at this time to add other illustrations, but $I$ will point out, that if suggestion can give alleviation or recovery to cases so obstinate in character as those I have here detailed, it becomes very evident that this means of relief offers permanent aid to ailments which are curable. This I have satisfactorily demonstrated in a list of cases which has become very long.

In closing I may also call your attention to the interesting fact, which I have proved over and over again, that, when it becomes necessary, in connection with suggestion to give specifics like iron and digitalis, they will, under suggestion, act vigorously where they formerly have failed to do so.

\section{Ulinital \&Department.}

\section{A CASE OF ADDISON'S DISEASE.}

BY KENELM WINBLOW, M.D., Visiting Physician, Newton Hospital, Newton, Mass.

ON May 10, 1895, I was asked to see a man in a boarding-house who had been vomiting for a few days. He was a French Canadian teamster, age twenty-eight.

\section{Family history negative.}

Personal history as follows: Has had gonorrhea and very probably syphilis. Had not been feeling strong for some time. Stopped work only a week before on account of weakness. Anorexia for weeks, and nausea and vomiting occasionally for a few days. On careful inquiry, subsequently learned that he had been failing for five months; getting thinner and weaker.

About Christmas, 1894, the patient went to Maine to work in the woods; and on returning in March, 1895, his friends said he looked as if he had been starved to death, and had grown so much darker that they joked with him about it and doubted if he were a white man. One of them observed to the writer that even the patient's lips had grown black.

The patient complained, when first seen, of vomiting, and, as the writer was only introduced casually while visiting another patient, bismuth and cerium, with a milk and lime-water diet, were recommended and the full import of the case was not perceived.

At the second and last time the patient was seen alive, two days after the first visit, he complained of great weakness and restlessness with much nausea and vomiting but no pain. Physical examination showed patient very thin; an angular curvature of the spine in the dorsal region; face and arms half-way to shoulder almost black; ocular conjunctivæ clear and white; pigmentation in groin and elsewhere, but not very well marked; pulse barely perceptible, thready90 per minute: temperature $99^{\circ}$, hands cold and clammy; tongue coated white, chest barrel-shaped; heart and lungs negative, abdomen flat, and nothing remarkable observed.

The patient was sent immediately to the Newton Hospital in an ambulance, as he had grown very weak the last few days. After spending three days in the hospital he died unexpectedly during the night.

He was fed on nutrient enemata, as vomiting was incessant. 'The urine was free from albumin and sugar ; specific gravity 1.015 .

At the autopsy the brain was examined by E. W. Hill, M.D., neurologist, and the chest and abdomen by Dr. D. L. Baker, who suggested the possibility of Addison's disease, and also by the writer. Nothing of any import was found except absence of all fat, subcutaneous or omental; cavities of body very dry and heart small. The supra-renal capsule was not demonstrable on the right, and on the left appeared to be small but normal.

Diagnosis of Addison's disease was made from the characteristic group of symptoms during life, namely : pigmentation of the skin, grave asthenia with nausea and vomiting, together with exclusion of other causes of disease or death.

Objection may be made that disease of the suprarenal capsule was not discovered, but this is not invariably present. The case is offered on account of its rarity. Osler has it 1 in 3,000 in foreign clinics and much rarer here. 